\title{
Anomalía y enfermedad en escritoras de inicios del s. $\mathrm{XX}^{*}$
}

\author{
Anomaly and Disease in Women Writers of the early $20^{\text {th }}$ century
}

\begin{abstract}
Ana Traverso
Universidad Austral de Chile, Facultad de Filosofía y Humanidades, Instituto de Lingüística y Literatura, Valdivia, Chile. Correo electrónico: anatraverso@gmail.com
\end{abstract}

Frente a los cada vez más legitimados y popularizados estudios científicos sobre las patologías femeninas y la naturalización de la enfermedad en la mujer, las escritoras del periodo introducen en sus ficciones agudas críticas contra la ciencia médica. A partir del análisis de la obra de cuatro autoras, proponemos tres ejes fundamentales en que ellas realizarían su denuncia. Mediante: 1) una nueva interpretación respecto de la "enfermedad" que cuestiona el sistema social y cultural que la produce; 2) el rechazo del diagnóstico de "enferma" y con ello las bases teóricas, presupuestos, métodos, en síntesis, la ciencia que lo fundamenta; y 3 ) a partir de la misma diferencia "natural" de los sexos, la formulación de modelos de mujer que se constituyen "superiores" moral y emocionalmente (sanas y estables) frente a sus pares masculinos más débiles e influenciables.

Palabras clave: escritoras chilenas, discursos médicos, enfermedad/salud, género

As a reaction against the increasingly legitimized and popularized studies about Chilean women's pathologies and the common acceptance of women's diseases, the female writers of the period acutely criticize medical science in their work. Based on the analysis of four female authors' writing, three ways to condemn this reality are suggested: 1) posing a new interpretation of the "disease" that denounces the social and cultural system that produces it; 2) rejecting the diagnose of "ill", together with the theoretical basis, presuppositions and methods of the science that supports the illness; and 3) based on the "natural" difference between genders, formulating models of women who are seen as morally and emotionally "superior" to their masculine peers (healthier and more stable), who are represented as weaker and more gullible.

Key words: Chilean Writers, Medical Discourse, Disease/Health, Gender

Para el cambio de siglo chileno, las mujeres habían comenzado a salir de sus hogares para integrarse al mercado laboral en las fábricas y escuelas, así como las

* Este artículo forma parte del Fondecyt 1120439, "Significaciones en torno a salud y enfermedad en la literatura chilena (1860 a 1930: Procesos modernizadores y representaciones corporales)", dirigido por Andrea Kottow. 
más acomodadas iniciaban sus primeras luchas por recibir educación y derechos de ciudadanía, haciendo estos cambios y reivindicaciones desde las ideas que afirmaban la diferencia natural y complementaria de los sexos. Pero, mientras el discurso médico cobra fuerza para argumentar que la naturaleza de la mujer (compasiva, intuitiva, débil e influenciable) la condicionaba a las labores del hogar, a riesgo de enfermarse o enloquecer, las mujeres replicarán, por su parte, que estas mismas diferencias las hacían superiores moralmente, posicionando, por sobre la razón, las virtudes éticas del sentimiento, la intuición, la compasión y el amor. Así entonces, el discurso femenino se vuelve desafiante a los valores de la modernidad ilustrada, reivindicando con ello otros paradigmas conceptuales como el misticismo, la espiritualidad, el budismo, la reencarnación, etc.

El intocado valor de la "salud" asociado a la razón, la modernidad y el progreso, se pone en cuestionamiento en los discursos de las mujeres, proponiendo que la enfermedad puede ser el origen y el síntoma de las mismas desigualdades que produce la modernidad. En este sentido, la enfermedad sería una condición que permite comprender al "Otro" en situación de subalternidad y, por lo tanto, un lugar de denuncia. Asimismo, las escritoras en sus textos literarios se encargarán de desconstruir los imaginarios masculinos sobre las mujeres, para formular modelos femeninos que se constituyen "superiores" moral y emocionalmente (sanas y estables) frente a sus pares masculinos más débiles e influenciables. En este sentido, vemos un rechazo del diagnóstico de "enferma" y con ello las bases teóricas, presupuestos, métodos, en síntesis, la ciencia que lo fundamenta.

Para ello, analizaremos los textos autobiográficos de dos escritoras, Teresa Wilms Montt y María Flora Yáñez, cuyos acontecimientos ocurren entre 1900 y 1930 y en los cuales se describen sus inagotables sufrimientos ocasionados por enfermedades crónicas, y que ellas explican invirtiendo los diagnósticos tradicionales de la ciencia médica: el malestar no tendría su origen en la rebeldía a la norma social -tal como sostendría el discurso normativo-, sino, muy por el contrario, lo generaría el propio disciplinamiento de los sexos, la vida burguesa y sus prohibiciones intelectuales, así como las obligaciones domésticas y maternales.

Junto con ello, los relatos de Inés Echeverría en La hora de queda (1918) y de Amanda Labarca en La lámpara maravillosa (1921), introducen personajes masculinos vinculados a la ciencia médica y al mundo intelectual y artístico, los cuales se sienten inclinados a "comprender" a la mujer desde lo que creen son sus habilidades y dominios: el conocimiento racional y el talento artístico. Sin embargo, en la búsqueda y aprehensión de su "objeto de estudio" se les enrostran los "métodos" del oficio, haciendo tambalear los fundamentos de la disciplina y con ello las antes incuestionadas capacidades intelectuales y artísticas, de la misma manera en que decae la también incuestionada salud. Mientras el hombre se acerca a la mujer para "aprehenderla" (con su ciencia) se le devuelve el reflejo de su vanidoso narcisismo que desmorona las bases en que funda su masculinidad y, con ello, aparece la figura de una mujer hasta entonces desconocida: equilibrada, sana, buena madre y leal esposa.

Así entonces, junto con cuestionar la subentendida disposición del hombre a la salud y la mujer a la enfermedad, estos textos ponen en entredicho el saber médicocientífico e incluso denuncian la patologización de la mujer como una forma de ocultar la violencia física y simbólica de las prácticas patriarcales que transforma el abuso (de la "violación", por ejemplo) en enfermedad (o "locura"). 


\section{La naturaleza enferma de la mujer}

Los actuales estudios sobre la historia de los argumentos médicos -a partir, principalmente, del trabajo de Foucault sobre la genealogía de los discursos sobre la locura- proponen que tanto la moral victoriana como los presupuestos darwinistas se habrían aliado en fundamentar la naturaleza enferma de la mujer. Así, Elaine Showalter (1987) analiza los discursos y los tratamientos médicos que se practicaron en Inglaterra entre 1830 y 1980, identificando tres períodos de la siquiatría moderna en que se cohesiona científicamente la asociación de la mujer con la locura; estos son: el victoriano (1830-1870), el darwinista (1870-1920) y el modernista (1920-1980). Si en la primera fase, el énfasis fue reforzar los roles asociados a la mujer (la maternidad, domesticidad y la prohibición de los estudios), justificando las enfermedades de las mujeres a partir del alejamiento de estas conductas, en el siguiente, la teoría darwinista sobre la diferencia natural de los sexos venía a reforzar científicamente la disposición social y cultural de las tareas asignadas a hombres y mujeres.

Diana Veneros -siguiendo la tesis de Showalter- ve en la ciencia médica de los siglos XIX y XX la formulación de un discurso contra las exigencias y demandas de las mujeres, principalmente en "los dos ámbitos en los cuales las reivindicaciones femeninas parecieron especialmente serias y amenazadoras para el corpus social. Uno de estos fue el asociado al control de la natalidad y el aborto. El otro a la educación femenina" (1995:136).

De esta manera, tanto en Europa Occidental como en Estados Unidos, un sector prestigioso y tradicional de científicos se amparó en argumentos frenológicos -en base a la estructura sexualmente diferenciada de los cráneos femeninos y masculinoso anatomoclínicos, para sostener que la biología de la mujer (cráneo, musculatura, sistema nervioso y reproductivo) explicaban su natural sensibilidad, irritabilidad, tendencia al agotamiento y al nerviosismo, así como su superioridad en intuición, percepción e imitación. El hombre, en cambio, al superarla en coraje, energía, intelecto e inventiva, quedaba naturalmente dispuesto para desarrollar actividades intelectuales, científicas y artísticas. Si la mujer, entonces, excedía sus capacidades biológicas al pretender desarrollar tareas intelectuales, por ejemplo, corría el severo riesgo de indisponerse y ver alterados sus ciclos reproductivos, sufriendo así de ataques histéricos, neuralgias, insomnios, abortos, esterilidad y, en las púberes, retardo de su aparato reproductivo. En otras palabras, contravenir la naturaleza femenina para estudiar o trabajar no sólo era una amenaza para la salud de la mujer sino para la reproducción de la especie: significaba el "suicidio de la raza" (Veneros, Showalter).

Pero tal como afirma la historiadora Claudia Araya, la ciencia médica no sólo estableció una conexión fisiológica entre el sistema reproductor y el nervioso; también asoció la biología de la mujer con la enfermedad en sí. De esta manera, Araya demuestra que el otro pilar de esta construcción científica fue la precariedad del límite "entre la fisiología y la patología femenina; es decir, entre la normalidad y la anormalidad. En la mujer, naturaleza y enfermedad se confunden a lo largo de la vida. Los ciclos exclusivamente femeninos, como la menstruación, la pubertad, el embarazo, la lactancia, la menopausia, aun siendo procesos fisiológicos, de acuerdo al modelo imperante en ese entonces eran capaces de provocar trastornos tan poco fisiológicos como la enajenación mental" (2010: 430). 
De este modo, la precaria salud de la mujer era necesario protegerla con sumo cuidado. Una inflamación crónica del útero o los ovarios podía afectar su aparato nervioso dando origen a una histeria, la cual a su vez -en la relación bidireccional entre anatomía y neurología- podía producirse por una educación viciosa o vida desordenada que afectara entonces a su organismo y aparato reproductor. Araya analiza detenidamente los informes (y los tratamientos) de los médicos frente al primer caso diagnosticado como histeria en Chile y que inaugura -según Armando Roa- la siquiatría moderna en el país. Así, desde los tratamientos que intervendrán directamente sobre los órganos reproductivos $-\mathrm{y}$ que alojarían la patología: útero, ovarios o vagina-, mediante su extirpación, la aplicación de la electroterapia o, más suavemente, la recomendación de baños fríos, se llegará a proponer la teoría de la "mímesis" -que continúa el Dr. Augusto Orrego Luco de su maestro, Jean-Martin Charcot- y que afirmaba el poder contagioso de la enfermedad, recomendando alejar a la histérica de otras de su sexo a fin de evitar el contagio imitativo.

Cuidar la salud de las mujeres correspondía a velar por la protección de sus hábitos domésticos y maternales. En este sentido, David Morris, en La cultura del dolor, recuerda los procedimientos del Dr. Mitchell para curar la histeria en los Estados Unidos de finales del siglo XIX, consistente en mantener a las pacientes acostadas en una cama, aisladas de su familia y alimentadas con una dieta de alto contenido calórico, sin otra actividad que la audición de "conferencias edificantes sobre los deberes hogareños y las obligaciones morales de las mujeres" (1993:130). Después de esta cura de descanso y engorda, le recomendaba a su paciente, la escritora estadounidense Charlotte Perkins Gilman: "Viva una vida lo más doméstica posible. Tenga usted a su hijo todo el tiempo... Descanse una hora después de cada comida. No tenga más de dos horas de vida intelectual al día. Y no vuelva a tocar un pluma o lápiz en el resto de su vida" (Cit. Morris 1993:130). Contrariamente a las recomendaciones de su médico, Gilman escribe The Yellow Wallpaper (1892), que narra la historia de una mujer que tras ser diagnosticada de neurastenia e histeria es amenazada por su marido-médico con someterla a un tratamiento similar al practicado por el Dr. Mitchell. Se decide finalmente por encerrarla en una habitación en donde enloquece definitivamente, alucinando con la imagen de una mujer encerrada en el papel mural de su pieza.

Este encierro de la mujer en la cárcel de los textos e imaginarios masculinos es el que intentarán denunciar las primeras escritoras del siglo en sus relatos. Buscarán escapar de la "habitación de la loca" en que son aprehendidas, definidas y encerradas por el médico-marido-crítico, evidenciando en el texto el espacio que les ha sido asignado. Es lo que afirman Gilbert y Gubar en su clásica y célebre obra, La loca del desván (1978). Su propuesta es que la primera generación de escritoras que lucha por insertarse en una tradición literaria abiertamente masculina -que en el caso europeo y norteamericano comienza a fines del siglo XVIII y durante todo el XIX, mientras en el latinoamericano estas expresiones son visibles a finales del siglo XIX y en los albores del XX, cuando comienza a constituirse un campo cultural autónomo y las escritoras hacen sus primeras incursiones profesionales en la escena literaria- lo hará desde una doble posición: desde la angustia o ansiedad de la autoría (dudando de su capacidad para convertirse en escritora) y desde la incomodidad y rebeldía ante las representaciones que la tradición masculina ha fijado en las páginas literarias sobre la mujer. Mientras el artista varón se angustia de no poder excluir de su obra la influencia 
de sus predecesores varones (Bloom), la mujer sentirá verdadero temor por el castigo (desprecio, burla, indiferencia, etc.) que recibirá de parte de los representantes del patriarcado por la imprudencia de aspirar a ser ella misma una artista. La "ansiedad enfermiza hacia la autoría" (Gilbert y Gubar 1978:78), al ver el fracaso o condena de sus pocas antecesoras, la llevará a actuar prudentemente (enmascarándose bajo el seudónimo masculino o reproduciendo imágenes tradicionales de mujer) o dejando expresar la "cólera ansiosa" (id. 92) para escapar del espejo que le ofrece el texto masculino ${ }^{1}$.

\section{Padecimientos de época y autodiagnósticos femeninos}

Si las páginas de la literatura y la ciencia médica masculina abundaban en ejemplos de enfermas o dueñas de casa sumisas recluidas en sus hogares, la escritora al decidirse a tomar la pluma se enfrentaba, por una parte, a estos imaginarios naturalizados en la comprensión de su género y, por otro, a la dificultad de ocupar (o "invadir") un espacio que no era el suyo. Escribir tenía las marcas de la "virilidad" y así fueron calificadas las primeras autoras canonizadas por los críticos chilenos: en masculinas y fuertes se convirtieron Gabriela Mistral y Marta Brunet para sus lectores, mientras sus restantes compañeras ocupaban los predecibles lugares de niñas sensibles y sentimentales (Oyarzún, Carreño). Escribir equivalía a realizar algo impropio para su género y, por lo tanto, la autora lo asumirá con “dolor" e intentando superar su anomalía.

Martina Barros Borgoño, una de las primeras intelectuales y feministas chilenas, se anima a traducir La Esclavitud de la Mujer de Stuart Mill y publicarlo en la Revista de Santiago en 1872. Viéndose, sin desearlo, inmiscuida en un pequeño escándalo social producto de ello, opta por renunciar a estas actividades intelectuales, pues: "No necesitaba de ellas y continué mi vida, entregada por entero a mis afectos más hondos, pero sin volver a hacer publicaciones que no convencían ni alentaban más que a los ya convencidos y causaban pavor a aquellas que deseaba estimular", sintetizando: "No nací para luchadora" (1872:127).

Pero al comenzar el nuevo siglo, Inés Echeverría (Iris), Teresa Wilms Montt, Amanda Labarca, Delie Rouge, Vera Zourof, Elvira Santa Cruz Ossa, María Monvel y tantas otras, habrían de atreverse, no sin manifestar innumerables dificultades ${ }^{2}$.

Nos interesa analizar dos relatos autobiográficos, escritos durante las tres primeras décadas del siglo: los Diarios de Teresa Wilms Mont, recopilados y publicados por Ruth González Vergara, que abarcan la infancia hasta la muerte de la poeta en 1921, y la autobiografía de María Flora Yáñez, que registra su infancia hasta convertirse en escritora. Ambos textos son testimonios de los dolores crónicos que debieron padecer las mujeres que deseaban rebelarse contra las normas impuestas a su clase y género, al desear incursionar en el mundo del arte y las letras.

Es lo que plantea Andrea Kottow respecto incluso de autoras adscritas a la generación del 50, cuyas escrituras expondrían un juego de inflexiones e inversiones a partir de la imagen histérica, "sin poder escapar a las formas en las que cultura patriarcal y autoría masculina la ha imaginado y representado. Casi obsesivamente las escritoras mujeres vuelven, como el asesino al lugar de su crimen, a los tópicos y la topografía que la tradición hecha por hombres ha fijado para ellas" (2014).

2 Carol Arcos, Lorena Amaro, Darcie Doll y Natalia Cisternas, entre otras investigadoras, han propuesto valiosas interpretaciones sobre la construcción autorial de estas primeras escritoras. 
Teresa Wilms Montt fue, sin duda, una de las escritoras más controvertidas de comienzos de siglo debido a sus transgresiones sociales ${ }^{3}$. Sus Diarios son la expresión de su crítica a la sociedad de la época a través de la autodiagnosticada patología del "mal de amores”4. Esta enfermedad sería síntoma del sufrimiento de la tierra, de los desposeídos, mientras la salud se encumbra como el ideal moderno que beneficia a unos pocos privilegiados: a los responsables del dolor del resto. Así, y siguiendo a Anz, este texto representa "un modelo de enfermedad que atribuye efectos patógenos al disciplinamiento moral de los afectos y las pasiones naturales" (36), donde la enfermedad es utilizada "para denunciar aquellas normas sociales consideradas como patógenas y para legitimar el llamado a reemplazarlas por otras 'más sanas"' (135).

En tercera persona y con una curiosa intención de autoanálisis, Teresa pequeña se mira en el espejo y se describe como una "niña extraña, tanto física como moralmente" (31). Se diferencia del resto de su familia en que goza melancólicamente "viendo una puesta de sol" o admirando "el encanto exótico de una flor" (32). También se diferencia en que ama la lectura -la cual le tienen estrictamente prohibida-y que ella practica a escondidas robando los ejemplares de la biblioteca. Mientras su familia -y probablemente la mayor parte de la población de la zona central que fue víctima del devastador terremoto de 1906- se horroriza ante los bruscos remezones de la tierra, la pequeña Teresa se impresiona del poder de la naturaleza y, sobre todo, de su propio coraje (una valentía para vivir y, sobre todo, para observar). Va desarrollando entonces lo que llama una "doble vista" (41), capaz de distinguir detrás de las sonrisas y los lindos vestidos, la verdadera cara de la hipocresía, la crueldad y la indiferencia... en su familia, su entorno social y la mayor parte de las personas con las que interactúa a lo largo de su vida. Esta mirada decepcionada de la humanidad se proyecta implacable:

Mi opinión sobre las mujeres es tristísima y muchas veces me avergüenzo de ser mujer... Sin ser malas lo aparentan, son débiles, orgullosas, profundamente estúpidas y vanas. iSon animales de costumbre! Los hombres, son malos de veras, viciosos, insensibles y egoístas. Son incapaces de un sentimiento delicado, que no sea para ellos mismos; pero son superiores... Cuando los veo elegantísimos, irreprochables, diviso a través de su indumentaria al mono, a la bestia carnívora, hambrienta y lujuriosa es claro que en ambos casos hay excepciones, pero son tan pocas (60).

Así, entonces, mientras “su admiración por la naturaleza aumenta a medida que disminuye su entusiasmo por sus semejantes" (41) -lo cual se observa, incluso, en la relación amable y empática con ratas, arañas, baratas y zancudos-, su opinión de los seres humanos le llevará a distinguir tajantemente entre los ejemplares "con alma", "que aman" y aquellos: "Pobres imbéciles, seres fríos, calculadores, de criterio estrecho, sin alma" (62). Esos “ $i[\mathrm{~N}]$ o pueden comprender el amor, porque es un sentimiento que no está al alcance de ellos! ¡No pueden comprender que para el verdadero amor, alma, materia y espíritu, no hay barreras!" (62).

Sugiero revisar la excelente biografía de Ruth González.

$4 \quad$ El autodiagnóstico del "mal de amores" también lo desarrolla Wilms Montt en su primer poemario, Inquietudes sentimentales (1917), tal como lo demuestra la tesis de licenciatura de Camila Flores. 
Este "dolor", que comienza en el momento en que es capaz de valorar las normas sociales en las que se desarrolla su educación y cultura, se torna en un malestar físico crónico, que a veces adopta el nombre de "tedio" o "hastío", pero que la mayor parte de las veces es "su mal": "Estoy resignada como un animal enfermo que no espera remedio, a morir de mi mal" (70). Así, "sanarse" equivale a dejar de sentir "dolor en el alma", a volverse "insensible" (como los seres que desprecia), de modo que la "resignación" a la enfermedad se vuelve también un deseo de mantenerla: “¡Oh ángel del dolor venid a mí! Quiero tus besos amargos, tus caricias turbadoras y enfermizas que hacen gemir de nostalgias..." (71).

A partir de acá, cualquier "diagnóstico" o "cura" a este "extraño mal" (200) no sólo revela su imposibilidad -“¡Qué ridículo llamar médicos para la enfermedad del alma!" (89)- sino su incomprensión: "No hay médico en el mundo que diagnostique mi mal: histeria, dicen unos, otros hiperestesia" (198). De este modo, el intento de "sanar" equivale a "anestesiarla", robarle el "dolor" y el "sufrimiento", "único bagaje que admite la barca que lleva al olvido" (201), como reza la suerte de epitafio con que concluye sus diarios ${ }^{5}$.

De este modo, la enfermedad se constituye en un lugar de resistencia contra la injusticia del mundo, y que se denuncia en el cuerpo sufriente del texto y de la enferma suicida. El precio que debe pagar la escritora por su denuncia, enfrenta la paradójica e insalvable alternativa de vivir para escribir (contraviniendo su plan de dolor-muerte-denuncia) o morir para denunciar (renunciando a su proyecto artístico). Pues aunque son escasos los momentos en que afirma sus motivaciones intelectuales y artísticas, en aquellas ocasiones cuestionará precisamente el proyecto sufriente que lo fundamentan ${ }^{6}$. En síntesis, nos parece que Wilms Montt no logra desarticular su crítica al sistema de la asociación intelecto/salud y pasión/enfermedad, donde el arte es un espacio entrampado en un saber que requiere de su enfermedad y sacrificio para su denuncia social.

La Historia de mi vida (1980) de Flora Yáñez es también un relato de malestares crónicos. Su primera molestia dice relación con la injusta exclusión de su padre, Eleodoro Yáñez, de la política nacional chilena, lo cual ocupa las primeras ochenta páginas de sus memorias. Lo que sigue corresponde al relato de sus constantes síntoma nerviosos que la acompañan desde los primeros meses de su matrimonio hasta la publicación de su primer libro; y en la última parte de la autobiografía, después de "haberse convertido" a su juicio -y el de la crítica- en una escritora, nos encontramos no con una descripción triunfante de la vida de la artista, sino con un cúmulo de incomodidades escénicas en el estreno literario. Así, el texto se convierte en la exposición de los padecimientos de una mujer que intenta ser escritora e intelectual a comienzos del siglo XX.

Una vez casada, Flora y su marido se embarcan para pasar una larga temporada en Europa. Allí, en plena "luna de miel” comienza a mostrar los primeros síntomas de enfermedad: "estoy muy delicada de salud y para no fatigarme con la agitadora

\footnotetext{
Dice: "Vida, fuiste regia, en el ruedo hueco de tu seno me abrigaste como al mar y, como a él tempestades me diste y belleza. Nada tengo, nada dejo, nada pido. Desnuda como nací me voy, tan ignorante de lo que en el mundo había. Sufrí y es el único bagaje que admite la barca que lleva al olvido" (201).

6 "Realmente me estoy abandonando demasiado al sufrimiento de amor. Ya es vicio. (...) Mañana me encerraré con mis libros y dedicaré por lo menos dos horas para meditación y organización de mis células cerebrales, actualmente en absoluto desorden" (101), concluyendo: "Quiero yo dominar mi corazón no que él me domine" (102).
} 
vida nocturna, permanecemos durante el día en nuestro hotel, dedicados a la lectura y al reposo" (1980:125). Al cumplir los tres meses de casados en Venecia comenta: "Todo es melancolía y me siento muy enferma", "mi flacura es horrible y aparezco pálida como un espectro" (125). Esto irá en aumento, sumándosele a ello, una "gran irritabilidad" (125-126) -lo cual se lo adjudica a la educación entregada por sus padres, quienes le habrían ofrecido cultura pero no habilidades para enfrentar la vida. Los malestares le impiden disfrutar su viaje: "No fui feliz ni en Italia ni en París, esta vez" (comparándolo con su viaje de soltera), debiendo permanecer la mayor parte del tiempo en cama. A ello se le suma su primer embarazo que junto con agravar su lamentable estado de salud empeora su ánimo con la repentina muerte de la pequeña al año y dos meses de vida, el mismo día en que nace su segundo hijo. Tampoco sobrevivirá la tercera hija, declarando "que todos los males me habían venido desde que me casé" (131). Sin embargo, se empeñará en tener más sucesores para llenar su “alma deprimida" (136) y así nacen Mónica y Alfonso. De esta manera, matrimonio y niños si bien parecen ser sus deseos son también la razón de su enfermedad: "Yo sigo enferma, con vértigos horrible. Es otro hijo que viene en camino" (137).

Con los "nervios en punta" (144), sensible y desilusionada a causa de la grave crisis política que afecta a su país tras la dictadura de Ibáñez del Campo y que trae como consecuencia el destierro del padre, afrontará los constantes cambios entre Chile y Europa. Así el viejo continente, cuna de la cultura y la ciencia médica, le ofrece diversión y sofisticación, a la vez que la promesa de una salud que no encuentra. Por ello frecuentará afanosamente diversos baños termales, clínicas e, incluso, sanatorios para uno de sus hijos, igualmente nervioso que ella. De Divonne des Bains, la clínica de hidroterapia más famosa de Europa en esos años, pasando por el reconocido Kindersanatorium en Ebenhausen, donde deja dos meses a su hijo Alfonso a raíz de una especie de "neurosis de ambiente" (187), para luego ser trasladada en camilla a la Clínica del Dr. Dichiara, en donde "por primera vez en mi enfermedad, me sentí bien cuidada" (213) pese a no recibir diagnóstico alguno, termina finalmente en una clínica en Alemania.

Flora Yáñez a pesar de que busca en la ciencia médica europea su recuperación -viaja especialmente de Chile a Alemania (acompañada de sus dos padres) para someterse a un tratamiento clínico- parece no conformarse con los diagnósticos que esta ciencia le ofrece. Su sufrimiento crónico, reducido a una "gran anemia” con recomendación de visitar los "Baños de Durkheim" (229), no resulta orientador. Por ello recurre a la terapia "del habla" del Dr. Schlomer en Berlín, al cual le sintetiza sus dolencias de la siguiente manera: "Había perdido mis dos niñitas y sufría atrozmente. Para no pensar, para no olvidar, me volví frívola, mundana. Como un escapismo. Abandoné la música, la gravedad de mis pensamientos, mis gustos nobles" (235).

Es ella quien identifica un problema de evasión a partir de una crisis personal y familiar, y quien encuentra el remedio: el regreso a sus "pensamientos" y "gustos nobles". Es ella, también, la que observa sus crisis nerviosas como una "enfermedad de época” (Hörisch)7, común a todo su entorno familiar: su marido es un "neurasténico”,

Jochen Hörisch define las "enfermedades de época" en correspondencia a una crisis epocal y a una conciencia de sus contemporáneos respecto del momento en que viven como diferente del que les precede en tanto crítico y amenazante. Síntoma de esta "crisis de época" son las correspondientes "enfermedades de época" cuyas posibilidades semánticas y somáticas revelan un saber sobre sí mismos y sobre (y en relación con) su tiempo. En cuanto al neurasténico, dice Hörisch, equivale a "estar tan nervioso, sensible, neurológicamente agotado y sin aliento, como correspondía a la agitada coyuntura entonces considerada como agitada (...) quien era neurasténico vivía consciente de su problema, 
a su juicio; su hijo padece de una "crisis de ambiente"; la madre será igualmente asidua a los sanatorios termales; el hermano, Jean Emar, elige un seudónimo con que expresa todo su tedio francés (j' en ai marre = estoy harto); y el mundo social en el que circula está constituido - dice- por "un grupo fastuoso y muy frívolo, compuesto de chilenos ricos y argentinos", "lejos del cual muero de tedio" (175).

Reconocidas entonces las causas de lo que llama su "desorientación" social, se vuelve hacia sus "inclinaciones místicas" y la espontánea necesidad de escribir: “¡Cuánto daría por realizarme, por publicar, por sentir ese contacto necesario con el público! Escribir es mi vicio, mi pasión, y no sé por qué mi inteligencia se consume en la aridez" (222). Así, entonces, irá recuperando "la salud y la paz" y perdiendo "esa agitación interior que me devoraba" (231), con lo cual se anima a escribir lo que llama "un esbozo de algo ¿novela?" (232). Vuelve la familia a Chile en 1932 y ella continuará con éxito la escritura de su novela. Abandona los diarios de vida y al año siguiente ya la ha publicado con el aplauso de la crítica: “Al fin seré escritora, novelista, como fue mi anhelo desde siempre" (245).

La “enfermiza angustia de la autoría” la supera María Flora cuando desaparecen las amenazas patriarcales, en su caso, las literales palabras condenatorias del padre, quien no deseaba que su hija hiciera el ridículo dedicándose a la escritura (242). Una vez que muere Don Eleodoro, ella se atreve a enviar el borrador de su primera novela a la imprenta y así comienzan a salir a la luz pública sus primeros libros. Tras reconocerse como novelista y "encontrar su misión" (246), deja de proyectar el foco obsesivo sobre sus enfermedades para comenzar a describir un nuevo entorno: el del mundo literario de su época ${ }^{8}$.

\section{La precaria estabilidad de la salud y el género: la superioridad moral de la mujer}

Escribir a comienzos del siglo XX, siendo una mujer burguesa, equivalía a romper con ciertas normas sociales - que no todas estaban dispuestas a subvertir-, a, eventualmente, ser tachada de loca y pervertida, como acusan a Teresa Wilms Montt, y a lidiar entre el imaginario de la "madresposa" (Lagarde) y la intelectual, dos personajes aparentemente antagónicos.

La propia Teresa Wilms, al tiempo en que duda si "dominar su corazón" para dedicarse al arte dramático, profundizar en la lectura, renunciar a sus hijas y optar por su amor prohibido, se autocondena a permanecer en el convento para demostrarle a su amante y a la sociedad ejemplos de virtud: "yo deseo ser amada y estimada como una mujer de bien" (68), y "a esos inhumanos cobardes sin entrañas los aplastaré con mi conducta. Han querido hacer de mí una pervertida y se encontrarán con que puedo darles lección de nobleza" (68).

o sea, vivía con una neurosis actual en todo sentido, a la altura de su época, y podía, por lo tanto, estar orgulloso de ello" (2006:47).

\footnotetext{
Creemos de interés complementar el caso de Yáñez con el de Inés Echeverría, quien expresa un duro enfrentamiento entre maternidad y realización personal en las páginas de su Entre dos siglos (1937). La maternidad, vivida como invasión, dolor y enfermedad, se antepone a sus proyectos intelectuales y "místicos-espirituales”, como enfatiza la académica Lorena Amaro, quien analiza los relatos de viaje de Iris, afirmando que "la autora permanentemente viajaba, tanto como turista como guiada por sus crisis nerviosas, en busca de recuperación, a distintas clínicas europeas. Por otra parte, cifraba en la escritura, pero sobre todo en su búsqueda espiritual y religiosa, el norte de sus preocupaciones. La maternidad, como se deja ver en estos diarios, para ella era más que un estorbo: era una fuente de sufrimiento. La dualidad cuerpo/espíritu aparece una y otra vez en su relato" (2013: 152).
} 
Entre el estratégico "modelo de virtud" y el de la excéntrica "artista" desinhibida, oscilará Teresa Wilms, pagando las consecuencias que ya sabemos. Esta será la imagen que la mayor parte de las escritoras intentará ocultar:

Yo era la única del sexo femenino en aquellas reuniones y así era demasiado consentida, pues todo me lo celebraban. Yo abusaba del licor, de los cigarrillos, del éter, etc., etc. También me gastaba ideas anarquistas y hablaba con el mayor desparpajo de la religión (en contra), y participaba de las ideas de la masonería. Escribía para los diarios, daba conciertos. Mis visitas eran a los hospitales, a las imprentas, acompañada de una tropa de médicos pijes y de pijes sin oficio, que me adulaban, y ponían por las nubes (Wilms Montt: 57).

Contra esa peligrosa imagen se esmeraron las "mujeres de bien" de la época, reivindicando, por el contrario, la "superioridad moral de la mujer" (Vera) por sobre la del hombre. Y es que amparadas en la tradicional división de los sexos, las mujeres apostaron por ensalzar las cualidades asociadas al suyo: el sentimiento, la espiritualidad, la compasión, el autosacrificio, la lealtad, etc., con fines reivindicativos y estratégicos. Según la socióloga Antonieta Vera, se trataría de "una retórica específicamente moderna a partir de la cual la figura de 'la mujer' pasa de representar la falla moral a encarnar el pilar moral de las sociedades. De acuerdo a este discurso, existiría un conjunto de cualidades 'propiamente femeninas' como la proximidad, la fuerza y la valentía en relación al cuidado de la vida, la capacidad de mediación, la madurez, etc. que vendrían a humanizar, renovar y limpiar la política" (204). Un discurso que sirvió para promover la labor "evangelizadora" de las maestras de escuelas rurales y las asistentes sociales hacia el pueblo, en el contexto de "las políticas públicas inspiradas en el 'saber científico' del higienismo y la puericultura" (205) y que utilizaron las feministas, "en esa lucha meritocrática por la igualdad en la que es necesario demostrar una 'buena feminidad nacional"' (212).

Para el caso de las escritoras, opera el deseo de reivindicar modelos de mujer capaces de enfrentarse al prejuicio de la artista loca, feminista, sabelotodo y enferma, con que los críticos plasmaron sus comentarios de libros (Traverso 2013). Anunciaban el advenimiento de la "Nueva Mujer", compañera y no rival del hombre, y, eventualmente, con todo el derecho para aspirar a igualdades en educación y ciudadanía:

Mi anhelo al interesarme en favor de la independencia y mayor cultura de la mujer no fue para hacerla rival del hombre, sino para constituirla en su digna compañera. La superioridad del hombre es indiscutible en todo lo que significa esfuerzo, capacidad mental y resistencia física. La mujer en cambio posee fuerzas morales, jamás superadas por el hombre, que constituyen su valer y poderío. En el hogar ella debe ser la soberana (Barros 1942: 296-7).

En los mismos términos de "virtud" y "reina del hogar", Elvira Santa Cruz Ossa proyecta el ideal femenino en base a sus cualidades tradicionalmente asignadas: "Yo me imagino a la mujer chilena del porvenir siempre virtuosa y adornada con todas las prendas femeninas que la hacen reina del hogar, consciente de sus actos, tolerante de las miserias humanas, compasiva ante el dolor, fuerte y enérgica para combatir los vicios y degradaciones que minan los cimientos de la sociedad" (1923). Para Inés Echeverría, dicha virtud se ancla en el sentimiento y la espiritualidad del alma 
femenina: "Por el sentimiento que es la ley del alma, la mujer se elevará siempre sobre el hombre que procede cerebralmente y que permanece, por lo tanto, en una esfera inferior" (1918: 136). A partir de la "estrategia de inversión" de las cualidades asignadas a los sexos -que postula Antonieta Vera-, Iris engrandece su "ignorancia" de estudios formales, pretendiendo de ella una visibilidad más nítida y sensible, que le permite autorizar su pensamiento y escritura:

Soy única y humildemente mística, sin estudios ni conocimientos de ningún género. Tengo mi mente limpia y desnuda de teorías o nuevos sistemas de organización social. La ignorancia de mi juventud continúa agravada por el acrecentamiento de la vida, de la ciencia y de los nuevos problemas que se han suscitado. A trueque de esta mente en blanco de historia, de ciencia y de libros, y de todos los conocimientos modernos, tengo una sensibilidad cada vez más afinada (404-5).

La lámpara maravillosa, uno de los pocos textos literarios de Amanda Labarca, es un claro ejemplo de esta exaltación de la "superioridad moral de la mujer" por sobre la vanidad y narcisismo de, en este caso, el artista. Eugenio Solís, pintor plástico de procedencia mesocrática, se casa con la bella hija de una viuda adinerada, propietaria de varias casonas en el barrio Loreto, heredando prontamente toda esta fortuna tras la muerte de su suegra y con ello el beneficio del tiempo libre para dedicarlo por completo a los quehaceres del arte. La inmortalización de su hermosa mujer en una obra que lo consagra en los círculos artísticos de moda, y que titula con el nombre del "Eterno Manantial", representará a la adolescente que ofrece al amado que ha de llegar, el agua de la fuente inagotable que es su belleza y su amor. Recibe con ello el más alto galardón de la época al que un artista nacional podía aspirar, pasando de ser famoso a ser un artista de moda. Estimulado con tal reconocimiento se propone un nuevo desafío que supere incluso su primer éxito: pintar una tela que llama "La lámpara maravillosa" donde se retrate "la gloria y el triunfo de la mujer" (24), y agrega: "La pintaré en el instante que, abierto sus ojos al amor, descubre el mundo por primera vez, como si sus años anteriores se hubieran arrastrado en la oscuridad y sólo ahora, gracias a la lumbre apasionada, le fuera dable percibir la realidad, la hermosura oculta, el misterio maravilloso de la vida" (24).

Obsesionado por retratar la belleza que produce en la mujer el amor heterosexual, la querrá ver, en su ópera prima, ofreciendo su amor incondicional al hombre abstracto que habrá de conocer para, en su segundo proyecto, revelarla iluminada (por vez primera) como una lámpara poblada de "genios ilusionados" que le brinda su mayor deseo: amar a un hombre y descubrir, por ende, el mundo.

Al narcisismo del joven artista, deseoso de verse retratado en los ojos enamorados de la mujer, le seguirá el descuido de su amada producto de lo que llama el/la narrador/a "su inmensa vanidad". Y es que henchido por el triunfo de su primera obra, Eugenio Solís se abandonará en la frivolidad del mundo artístico, perdiéndose en aventuras y conquistas amorosas al intentar buscar a la nueva modelo para su proyecto. A su esposa, Matilde, empero, "no le dolían sus ausencias si al cabo de ellas tornaba gozoso, halagado -como ya anunciábamos- de su inmensa vanidad de artista y de hombre" (29).

Una actriz de la Compañía de María Guerrero, la famosa artista dramática madrileña del cambio de siglo, será la primera escogida para concretizar a la 
"mujer lámpara”. Pero además de estimular una nueva ausencia del cada vez más descontrolado artista, esta vez partiendo rumbo a Concepción, la visita, por lo visto, no conducirá a cuajar la obra. Una segunda modelo que llevará Eugenio a su taller, esta vez una impúdica poeta y narradora "con un alarde de despreocupación y de amoralidad, completamente de acuerdo con las teorías literarias que profesaba" (41), además de ser "hermosa, atrevida y sensual, se preciaba de Jorge Sand en la pequeña comunidad artística de Santiago" (41). La mujer, más allá de burlarse de la "añejez colonial" en que vivía Eugenio, tampoco contribuirá a realizar la obra.

Pero el relato de Labarca desde el comienzo nos pone en el escenario otra figura masculina igualmente importante que Eugenio Solís. Se trata de Andrés Hidalgo, el amigo paralítico del joven pintor, que "bohemio por necesidad", "había errado solitario y sin familia por los caminos de la vida" (19). Mientras "Eugenio Solís alto, fuerte, ágil, se diría un héroe griego (...) Andrés Hidalgo, en cambio, era un hombre olvidado de los dioses. Una parálisis infantil le había marcado desde la niñez con su sello implacable. El tórax sumido se asentaba sobre unas piernas endebles y contrahechas, de pies deformes, que le obligaban a apoyarse en dos soportes para andar y aun así, lo hacía torpe y dificultosamente" (17). Su trato amable, no obstante, lleva a esta joven pareja a incorporarlo para siempre en la casa familiar.

Así se irá desarrollando este curioso trío, que en un comienzo compartirá las ambiciones de Eugenio, para luego - con las cada vez más largas ausencias del cónyuge- centrarse ambos (Matilde y Andrés) en la mantención del hogar. De las deudas y los consecuentes embargos y remates, la esforzada Matilde recurre a su vieja máquina de coser, mientras que el talentoso paralítico hará de sus caricaturas cómicas, productivas ilustraciones para revistas, y diseño publicitario para el incipiente mercado automovilístico. Pero su mayor contribución será mantener en alto el ánimo de la mujer, teniendo la certeza, eso sí, y la melancolía también, de la imposibilidad de su amor hacia esta sana y bella dama en contraste con lo que él llama "su deformidad".

Pues “[N]o amaba a Matilde con el egoísmo tiránico del hombre sano, fuerte, robusto. De haber sido sano, no habría podido concebir la dulcedumbre exquisita que sólo entienden y han menester las almas enfermizas y tiernas; de haber sido fuerte, hubiera ignorado la compasión que es una debilidad que simpatiza con otra debilidad; de haber sido robusto, sus pasiones fogosas como piafantes corceles, habrían pisoteado en su carrera las florecillas del amor callado y humilde..." (38).

La fiel e incondicional Matilde -que afirma orgullosa: "Yo no me he casado, Andrés, para compartir la dicha de Eugenio. Me casé para compartir su vida, fuera cual fuera, con todas las amarguras, con todas las penas que tuviese, y con el favor de Dios, pienso seguir así hasta que me muera" (65)- recibirá finalmente a un Eugenio afiebrado y enfermo de tifus (enfermedad mortal en ese entonces), el que con el amor dedicado de su mujer irá recuperando lentamente su antigua salud.

El relato finaliza con el momento epifánico en que Eugenio y Andrés observan venir a Matilde cantando y con un ramo de flores en la mano, tal como imaginaron ambos la representación de "La lámpara maravillosa" alguna vez. Así el egocéntrico

Porque "la lumbre brota de sus entrañas" y "es ella [la mujer] al mismo tiempo la lámpara, y el aceite, y la portadora de la luz" (25), dice Eugenio Solís. 
artista interpreta en ello una lección para sí mismo que, tal como la vieja historia de las Mil y una noches, enseña que la ignorancia de intercambiar la lámpara maravillosa por lámparas nuevas se paga con fatigas, errancias y penurias; mientras su generosa mujer observa: "No, repuso ella, yo no habría sido capaz de mantener el aceite de tu lámpara. Andrés la ha alimentado, él, que con su cariño vigilante ha alejado las rachas que pudieron extinguir su luz" (74). Inspirado el pintor concluirá el cuadro prometido.

Así, Eugenio y su alter ego Andrés concentran en la figura del artista los dos polos de la salud y enfermedad, fácilmente reversibles. El sano, hermoso y fuerte se vuelve enfermo producto de su orgullo, soberbia y vanidad, mientras que el postrado y débil paralítico viene a ser el sostén de la mujer abandonada. Ambos, desde sus respectivos talentos intelectuales y artísticos, intentarán describir, comprender y conocer a la mujer, viendo el primero en el enceguecido espejo el amor que él causa, mientras que el segundo se identificará con la compasión y debilidad que cree compartir con ella. Proyecciones de sus deseos y perspectivas, la mujer se vuelve el enigma que el artista busca atrapar en su retrato.

Junto con ello, el texto nos antepone a su vez a dos tipos de mujer: la mujer artista (que encarnan las dos modelos del pintor) y la mujer dueña de casa (nuestra heroína). El primer tipo es presentado en el texto desde los celos y la envidia femenina como "impúdica", "atrevida", "hermosa", "sensual" y "libre", mientras la dueña de casa, muy bella y fiel, se aburre infinitamente en su casa, cosiendo, escuchando al paralítico y esperando a su marido parrandero. ¿Por qué la feminista Amanda Labarca, promotora e historiadora de la educación de la mujer, parece tomar partido por este modelo del "ángel del hogar" (silenciosa y silenciada) en lugar de la escritora deslenguada e independiente?

Pareciera que este "modelo de virtud", más que satisfacer el imaginario de la escritora, busca complacer a sus lectores masculinos, mostrándoles la manifestación del "ideal de una esposa" como soberana del hogar, compañera, nunca rival del hombre, y que, por el contrario, ilumina su camino, manteniéndose sana, virtuosa y fuerte para sobreponerse a todas las amenazas y peligros. Esta "mujer ideal", que casi no habla, que casi no piensa, y que sus escasos diálogos buscan reafirmar el estereotipo de sus compañeros varones, parece ser ciertamente aquella "lámpara maravillosa" que pintaron con su imaginación ambos varones (Eugenio y Andrés). ¿Dónde está la verdadera mujer, la de "carne y hueso", esta vez, pintada por la propia escritora?

Intentaremos responder a esta pregunta a través del análisis de un texto de Inés Echeverría, titulado "Tette de Linotte" (cabeza de chorlito) y que fue publicado en el conjunto de cuentos La hora de queda (1918). Al igual que en el anterior, su protagonista es un varón orgulloso de sus capacidades intelectuales, y con las cuales intenta aprehender a la mujer: en este caso, a través de sus conocimientos sobre las patologías femeninas. Ambos (artista y médico) enfrentan sus percepciones y estereotipos de la mujer sobre un espejo que va devolviéndoles sus imaginario artístico-médico-genéricos y, con ello, el reverso de sus incuestionados oficios, los atributos racionales/creativos, y la asociación salud y virilidad.

Como decíamos, se trata de un reconocido médico de la Salpetrière, que asiste a un congreso científico con más de 300 especialistas en Divonne de Bains (la clínica que frecuenta Flora Yáñez) con el fin de exponer las novedades científicas en el área de la neurosis femenina. Ya el primer día se ve imposibilitado de participar del intercambio científico al obsesionarse con una mujer que deambula por la clínica. Su austera vida de 
empedernido soltero dedicada exclusivamente a la ciencia y privada de cualquier otro placer, lo llena de orgullo y jactancia: "Mi vida, había transcurrido en una normalidad perfecta dentro de un método invariable" (60). Pero la seductora mujer, en apariencia una enigmática femme fatale, se transforma en el obstáculo que lo desvía de sus objetivos para, en su lugar, sugerir otros discursos que permanecen en el misterio sobre el mundo material y sensible (como la reencarnación, el mentalismo, la sugestión y la fatalidad).

De la certeza en que "las leyes naturales" "a veces esquivas, pero siempre normales" - pues con ello sólo buscan "resaltar su implacable lógica" (61)-, le sucede una desconfianza en su capacidad de análisis e interpretación, lo cual se constituye en un desconcierto disciplinar junto con la consecuente crisis de su Ego como médico y varón: "Yo, un médico altamente graduado, profesor en la Salpetrière, un operador sobre la voluntad humana, sufría un eclipse en mis conocimientos, una depresión de todo mi ser" (64).

Este cuestionamiento de los fundamentos teóricos de su profesión le impiden entonces formular un diagnóstico sobre la mujer, descartando por insuficiente toda la variedad de patologías típicamente femeninas: “Sería una de tantas neuróticas, détraquées, o maniáticas, de esas que constituían mis apasionantes casos? Ofrecía síntomas, ciertamente, pero había en ella un elemento nuevo, que confundía mis experiencias. Me quedé paralojizado, sin saber qué diagnóstico formular, para mis adentros" (66).

Más aun, mientras ella se resiste al diagnóstico, él se va transformando para sí mismo en uno más de los habituales casos de "neurosis". Al recibir una esquela de la mujer en que lo invita a su alcoba, comenta angustiado: "la cita me puso en ese estado de inquietud febril, en que había visto a tantos de mis "casos", víctima de la debilidad amorosa, que hace al hombre de razón inferior a la bestia y en la mayoría de las veces pueril como un niño" (75).

Así, del cuestionamiento de la patologización de la mujer como neurótica, histérica o maniática, le sigue otra clasificación estereotípica, ya no dentro del discurso clínico sino en la lógica de las imágenes míticas tradicionales, que vinculan enigma y seducción a la figura de la femme fatal. Ninfa, serpiente, felina caprichosa y oriental, serán algunas de las asociaciones que asigna este desconcertado médico a su inapresable objeto de estudio.

Sus galas orientales la hermanan a las populares mujeres fatales de la literatura del siglo XIX como Salomé o Medusa, y la sitúa en el estrecho límite de los placeres y los vicios. Fumadora, bebedora y aficionada al juego, la mujer aparece cercana a los animales exóticos y en ambientes orientales: entre biombos, perfume a sándalo y rodeada de tapices, pieles y flores fantásticas, es comparada con una "maga" o "esfinge", la cual -a juicio del médico- la hacen percibir no como "una mujer - dice-, ni como ante una diosa, sino cual si fuese el universo en espléndida manifestación" (76).

Entre la paciente enferma e inhabilitada y la villana destructiva, el médico intentará defenderse de la mujer y su poderosa amenaza devastadora, aplicando para ello herramientas metodológicas que le son cada vez más inútiles. Finalmente, ella lo cita a su alcoba donde le expondrá el enigma de la "sugestión": En los tiempos del Emperador Augusto, yo que entonces pertenecía al sexo, llamado por ironía fuerte, siendo que en realidad la potencia del músculo va en relación inversa a la superioridad del espíritu, pues entonces, mi Ego de sexo positivo, sufrió algún menoscabo material del Ego de Ud., negativo en aquel tiempo (77). 
Es a causa de esta relación de desigualdad de las fuerzas de los géneros y al antiguo daño que habría sufrido ella siendo varón, que el ahora médico deberá pagar literalmente la "vieja deuda". La paga en términos materiales, en una primera instancia, cuando siente el impulso de dejarle en herencia todo su dinero a la mujer. Y también la debe pagar por medio de lo que ella llama "la humillación" de su disciplina y su género, cuando este médico varón (dos términos necesariamente asociados) ve cuestionados los objetivos, método de análisis, supuestos teóricos, objeto de estudio, resultados... en fin, toda la disciplina clínica que practica, lo mismo que la supuesta superioridad, racionalidad e identidad masculina que lo definirían. Las aparentes equivalencias de género resultan ser condiciones intercambiables cuyos rasgos a su vez se constituyen en términos arbitrarios, donde la fortaleza asociada al varón resulta pura ironía a juicio de la vindicadora mujer.

Ante la imposibilidad de otorgarle un adecuado diagnóstico a la mujer, que se resiste a convertirse en su paciente, el médico se ve recurriendo a la opinión de otro experto: el especialista encargado de la clínica de hidroterapia, el cual nos aclara el, a estas alturas, desautorizado médico, "era un hombre de perfecto equilibrio" (80). Pero para su sorpresa, el juicio clínico del colega viene a ser una exaltación de la salud y normalidad de la mujer, quien se desenvolvería dentro de los estrictos cánones morales de la sociedad de la época:

Es mi cliente. Raras veces he visto una naturaleza tan normal. Juega, trasnocha, ejecuta caprichos inverosímiles y nunca sufre depresiones nerviosas, que indiquen desgaste excesivo o cualquiera perturbación de surmenage (...) Es una original, que posa de extravagancia, pero sin apartarse de las grandes líneas morales. Nunca ha tenido historias galantes. Sus numerosos admiradores quedan siempre a respetuosa distancia de su intimidad. Tiene dos hijos y se ocupa de ellos inteligentemente. Su marido es un ser positivo y ambos se guardan lealtad y respeto. En su misma pasión por el juego observa una medida que no traspasa nunca. Ha dedicado una fuerte suma, 100 mil francos, para satisfacer este capricho. Y lo curioso es, que después de muchos años, esta suma confiada al azar de todos los tapetes verdes, de sus continuos cambios de lugar, ni se ha duplicado ni se ha perdido. Parece que manejara el secreto de la Suerte, y que sólo se propusiera, iépater les bourgeois! (81).

El texto nos expone una tercera posibilidad de diagnóstico para la mujer, que no es ni la "enferma-neurótica" ni la "malvada-destructora", sino la de una extravagante que, por lo demás, se ajusta a las reglas morales de la época (perfecta esposa, madre ejemplar, sin adulterios ni vicios). Es el juicio más condescendiente que ofrece el círculo médico sobre la mujer. Sin embargo, y tal como ocurre en La lámpara maravillosa, queda en evidencia la necesidad de patologizar la diferencia genérica desde la mirada masculina, donde la ansiedad del diagnóstico se enfrentará en el espejo textual con la imagen inversa que le refleja la precariedad de todo su "saber patognóstico", en términos de Jochen Hörisch. Con ello, el crítico propone a la literatura -en tanto textualidad sintomática de la "crisis de época" y sus consecuentes "enfermedades de época", ya mencionadas- como un "discurso perturbado, enfermo y pato-lógico" (52), que revela un conocimiento (gnoseología) sobre la patología y, a su vez, donde las enfermedades devienen conocimiento. De esta manera, el valor "patognóstico" -neologismo que hace corresponder la lógica de la enfermedad con la lógica del conocimiento- del texto que nos ocupa, devuelve el diagnóstico tradicionalmente asignado a la "enferma- 
mujer" hacia el médico, asumiendo en su cuerpo la "sugestión" o "mímesis" en términos del Dr. Orrego Luco siguiendo a su maestro Charcot-, la "neurosis", etc., para con ello vivenciar la realidad desde una experiencia de sensualidad y empatía (que apenas logra disfrutar), y desde ahí poner en cuestionamiento los dictámenes patologizantes de la medicina. Lo que el médico llama "enfermedad" es la "Otra-Mujer", y los términos con que la define evidencian los temores que amenazan su propia identidad: descontrol, irracionalidad, pasión, sugestión. Su sexo, llamado irónicamente "fuerte" -dirá la misteriosa mujer-, se ha amparado en la ciencia médica para encumbrar su masculinidad, siendo ésta amenazada al intentar comprender el mundo desde otros paradigmas cognoscitivos.

\section{Locura femenina o el abuso masculino sobre la mujer}

"Miserias ocultas" de Inés Echeverría, otros de los cuentos de La hora de queda (1918), relata la historia de una antigua sirviente, quien fiel a los intereses de sus patrones y, por lo mismo, un ejemplar casi extinto en la nueva configuración social del agitado comienzo del siglo XX -según la narradora, sufre las consecuencias de estas transformaciones. Se trata de "la plebeya, que tiene dentro de su condición humilde, los más bellos atributos de las grandes razas: la altivez, la abnegación, la fidelidad y una sorprendente pureza de costumbres" (97-8):

El vicio no las ha contaminado nunca [a este tipo de sirvientas]; las peores acechanzas las han dejado inmunes como si llevaran en el alma un talismán secreto que las hace inviolables. La canallería popular tampoco las alcanza. Han nacido en nuestras viejas casas, y mueren al servicio de nuestra clase social... ¿Cómo no hemos de sospechar que este ser anónimo y raro lleva la mitad de nuestra sangre, al ver que nunca fermenta en sus corazones, ese odio de clases, que trae al mundo el legítimo plebeyo...? (98).

Así hablan y reflexionan dos distinguidas damas sobre los cambios sociales del nuevo siglo, donde está implícita la pérdida de la hegemonía oligárquica, la ascendencia de la burguesía minera e industrial y sus consecuentes tratos con la clase trabajadora, cada vez más cansados de los abusos de los grupos dominantes. La narradora se refiere a su compañera de plática como perteneciente a esa antigua y noble aristocracia, de la cual evidentemente también ella es parte. Pero si bien estos cambios que se denuncian conllevan una nostalgia respecto de la antigua disposición de las fuerzas sociales, asimismo registran en el comentario anterior la reproducción histórica de la violencia del patrón sobre la sirvienta en esta sospecha por la "sangre aristócrata" que habría en ella.

Ambas damas conversan sobre la desgraciada vida de una sirvienta, Lorenza, quien casada con un esforzado inmigrante francés, tiene dos hijas: Matilde, que "no parecía pueblo, no tenía la sombra ni la rudeza de los fragosos bosques de Arauco" (101) sino que, por el contrario, era fina, delicada, "la normalidad hecha mujer", mientras que Genoveva, más morena y robusta, muere paradójica y sorpresivamente de una enfermedad violenta y sin causa:

Durante el tiempo que Lorenza fue casada, había cambiado mucho el mundo de los criados. Ya no tenían respeto por sus amos, ya no cuidaban las cosas como propias. Ya no se decía 
como antes: los patrones cual si se nombrara a los padres. Ahora se decía los ricos y entre todos se aleonaban para no guardarles la plata a los ricos, para no gastarse los pulmones por los ricos, etc.

Unos y otros habían cambiado. Las señoras no se apegaban a los sirvientes, que entraban, salían y se mudaban todos los meses y los sirvientes en un ansia de perpetuo cambio y de altanería, decían: A quien remuda, Dios le ayuda (109).

Lorenza, en cambio, que pertenecía al tipo antiguo de criada resulta ser un problema en estas casas de nuevos ricos, donde los patrones, al intentar evitar diferencias entre sus trabajadores, optan por despedirla ante la evidencia de los rencores que genera en estos "aleonados" sirvientes. Asimismo, mujer esforzada y trabajadora, una vez muerto su marido se empeñará en darle educación "decente" a su hija en un internado para niñas de clase media. La influencia de la "raza" francesa por parte del padre, la distinguirá del resto de las niñas "oscuras y toscas, con pies deformes y manos groseras” (111), destacándose incluso por su conducta y buenas calificaciones.

Madre e hija quedan al cuidado de una mansión casi vacía durante las vacaciones de verano de la familia, contando solo con la presencia del "caballerito" que observa detenida y codiciosamente a la joven. Siguiendo los impulsos de la tradición, se arroja sobre la chica, dejándola para siempre con los “ojos extraviados". La violación le hace "perder la razón" a la joven sin que el padre ni ningún otro miembro de la familia del culpable se haga responsable de la agresión: "Nunca saben ustedes cuidar a sus hijas" - exclama por el contrario el progenitor. Actitud que la aristocrática narradora denunciará indignada comentando: “¿No son las pobres creaturas las víctimas obligadas de la lascivia masculina? Allí no hay complicaciones ni reclamos. A lo peores delitos sigue el silencio, el olvido... ¡Así es la naturaleza, piensan tranquilos en su interior! ¡Cosas de la vida!” (119-20).

La violación transforma a la joven en la culpable del abuso, no sólo a partir de la reacción de la familia del criminal, sino según las religiosas a las cuales acude Lorenza para buscar complicidad y de acuerdo a la propia fisionomía que adquiere la muchacha, en donde ya "no le quedaban huellas de juventud, ni de belleza... ¿Quién hubiera imaginado la gracia amable de esa niña, la pureza virginal de aquella alma, ante la loca procaz, desvergonzada, de risas histéricas, de movimientos espasmódicos, de mirar airado? Para todos era sin duda: ¡la Perdida! ¡Y perdida lo estaba para siempre!" (121).

El texto pretende ser una denuncia de la que llama la "impunidad del macho soberbio" (122) en donde la "ocasión" facilita el impune crimen llegando "el hombre a las más indignas violencias" (122). Junto con ello, exhibe la violencia de las designaciones: "loca", "histérica", "perdida" con que se encubre el delito masculino sobre el cuerpo de la mujer. La "pérdida" del honor y la virginidad condicionan la irreversibilidad de su suerte, recibiendo en su cuerpo la culpa del delito ajeno. En el cuerpo de la "loca" o la "histérica" encontraríamos las huellas de un crimen silenciado, en el cual estas escrituras indagan para develar sus culpabilidades.

Como se ha visto, las estrategias que utilizan estas autoras para afirmar la feminidad y la categoría mujer, sin desmarcarse de los términos adjudicados al género, comporta una fórmula "de inversión" (Vera) de sus signos tradicionales, 
donde la enfermedad se transforma en un síntoma de la rebeldía femenina que permite comenzar a comprender, aunque de manera incipiente, a ese Otro Mujer. Estos textos de denuncia, más que de mujeres enfermas, articulan las siguientes estrategias discursivas:

La reivindicación de la enfermedad: consistente en enaltecer el estereotipo de la "mujer doliente" (cercana a la naturaleza, a las emociones y los débiles) para expandir así una aguda crítica a la sociedad de la época y enrostrarle su indiferencia e inhumanidad. Al transformar la enfermedad en su poética, en donde el arte y el intelecto se alían con el “dominio del corazón”, la voluntad y, finalmente, la razón, la escritura se vuelve enemiga de un proyecto estético en cofradía con las nociones de oficio, profesión e investigación intelectual, para, en cambio, abrazar concepciones tardo románticas y decadentistas cercana a la "expresión de sentimientos". Poéticas como esta contribuirán a valorar la escritura femenina como aficionada y sentimental.

El rechazo al diagnóstico de enferma: se transformará en una importante rebelión de las autoras contra las marcas negativas asignadas a su género. La estrecha relación entre enfermedad y mujer por parte de las propias escritoras, se observa en el entramado que articulan entre enfermedad y maternidad en oposición a salud y vida mística e intelectual. Al reivindicar su género, transgreden en muchos de los textos la mistificación de la maternidad que ellas mismas como feministas exaltaron en sus discursos, relativizando así este modelo de salud, afecto y virtuosismo. Sin atreverse aun a posicionar nuevos modelos de mujer, las autoras concentran sus críticas en la desarticulación del imaginario masculino sobre la comprensión de la Mujer y con este la naturalización de la enfermedad en la mujer.

La crítica a la ciencia médica: denuncia la violencia simbólica con que la institución clínica define a la mujer como enferma y loca, y reserva para el hombre los términos de normalidad y salud. Ante ello, la autora ofrece otras comprensiones cognoscitivas de la realidad -como el misticismo, la teosofía, el espiritualismo y la reencarnación- que se distancian del paradigma científico, para cuestionar así las inamovibles identidades de género. Al desestabilizar la categoría sexo-género y sus supuestos atributos, evidencia el entramado ideológico con el cual la ciencia médica ha buscado configurar un yo-masculino racional y relegar a "la Otra" en que teme convertirse bajo el nombre de Mujer.

En síntesis: la dificultad de denunciar el imaginario masculino desde el mismo lenguaje clínico, estereotípico y social tiende a entrampar a las autoras de los albores del siglo, sin lograr muchas veces escapar del espejo que la tradición literaria masculina le enrostra. Al acoger en su literatura el imaginario que se quiere denunciar, las construcciones de mujeres que intentarán estas nuevas escritoras se visten incómodamente con los trajes tradicionales, reflejando el revés gastado del estereotipo sin todavía poder arrancar del espejo masculino.

\section{OBRAS CITADAS}

Amaro, Lorena. 2013. "Encuadres de la memoria: cartografías y genealogías en los textos de Martina Barros e Inés Echeverría". Anales de Literatura Chilena 19: 137-157.

Anz, Thomas. 2006. “Argumentos médicos e historias clínicas para la legitimación e institución de normas sociales”. Literatura, cultura, enfermedad. Bongers, Wolfgang y Olbrich, Tanja (editores). Buenos Aires: Paidós. 
Araya, Claudia. 2010. "Mujeres, médicos y enfermedad mental en la segunda mitad del siglo XIX". Historia de las mujeres en Chile. Stuven, Ana María y Fermandois, Joaquín (editores). Santiago: Taurus. 427-454.

Barros, Martina. 1942. Recuerdos de mi vida. Santiago: Editorial Orbe.

Bloom, Harold. 1976. La angustia de las influencias. Caracas: Monteávila.

Carreño, Rubí. 2002. "Una escena crítica: estereotipos e ideologías de género en la recepción crítica de Marta Brunet y María Luisa Bombal". Anales de Literatura Chilena 3: 43-51.

Echeverría, Inés (Iris). 1918. La hora de queda. Santiago: Universitaria.

Echeverría, Inés (Iris). 1918. "Casa de Muñeca, a través de la mujer moderna". Alma femenina y mujer moderna (2001). Subercaseaux, Bernardo. Santiago: Cuarto Propio. 131-136.

Flores, Camila. 2013. "La extraña enfermedad del mal de amores: la histerización en el poemario Inquietudes sentimentales de Teresa Wilms Montt”. Tesis para optar al título de Profesor de Lenguaje y Comunicación. Valdivia: UACh.

Gilbert, Sandra y Gubar, Susan. 1998. La loca del desván. La escritora y la imaginación literaria del siglo XIX (1978). Madrid: Cátedra.

González, Ruth. 2009. Teresa Wilms Montt. Un canto de libertad. Santiago: Grijalbo

Hörisch, Jochen. 2006. "Las épocas y sus enfermedades. El saber patognóstico de la literatura”. Literatura, cultura, enfermedad. Bongers, Wolfgang y Olbrich, Tanja (editores). Buenos Aires: Paidós.

Kottow, Andrea. 2014. "Ninfómanas, ciegas y mudas: enfermedad y escritura en la literatura de Margarita Aguirre, María Elena Gertner y Elisa Serrana”. Taller de letras 54: 57-72.

Labarca Hubertson, Amanda. 1921. La lámpara maravillosa. Santiago: Casa Edit. Minerva.

Morris, David. 1993. La cultura del dolor. Santiago: Editorial Andrés Bello.

Lagarde, Marcela. 1993. Los cautiverios de las mujeres: madresposas, monjas, putas, presas y locas. Universidad Nacional de México. Distrito Federal México.

Oyarzún, Kemy. "Género y canon: la escritura de Marta Brunet”. Cyberhumanitatis 14 (2000). Consultado el 19 de mayo de 2013, de http://www.cyberhumanitatis.uchile.cl/index.php/ $\mathrm{RCH} /$ article/viewArticle/9115/9112

Roa, Armando. 1974. Demonio y siquiatría: aparición de la conciencia científica en Chile. Santiago: Andrés Bello.

Santa Cruz Ossa, Elvira. 1923. "Los derechos de la mujer en la V Conferencia Panamericana, en El Mercurio, 22 de Abril de 1923.

Showalter, Elaine. 1987. The Female Malady. Women, madness and English Culture (18301980). London: Virago Press.

Traverso, Ana. 2013. "Ser mujer y escribir en Chile: canon, crítica y concepciones de género". Anales de literatura chilena 20: 67-90.

Veneros, Diana. 1995. "Consideraciones médicas decimonónicas en torno a género, salud y educación”. Dimensión histórica de Chile 10: 135-53.

Vera, Antonieta. 2012. "'La superioridad moral de la mujer': el estado higienista y la buena feminidad nacional (Chile, 1920-1930)". En Colonialidad/Decolonialidad del Poder/ Saber. Miradas desde el Sur. Valdivia: Ediciones UACh: 211-222.

Wilms Montt, Teresa. 1994. Diarios. En Obras Completas. González, Ruth (editora). Santiago: Grijalbo.

Yáñez, María Flora. 1980. Historia de mi vida. Santiago: Nascimento. 
